\title{
Correction to: On Balayage and B-Balayage Operators
}

\author{
Maria Nowak ${ }^{1} \cdot$ Paweł Sobolewski $^{1}$
}

Published online: 15 February 2020

๑) Springer-Verlag GmbH Germany, part of Springer Nature 2020

\section{Correction to: Computational Methods and Function Theory (2019) 19:509-518 https://doi.org/10.1007/s40315-019-00277-w}

In the original publication, article title was incorrectly published as 'On Balayaga and B-Balayage Operators'. The correct title should read as 'On Balayage and B-Balayage Operators'.

Publisher's Note Springer Nature remains neutral with regard to jurisdictional claims in published maps and institutional affiliations.

The original article can be found online at https://doi.org/10.1007/s40315-019-00277-w.

$\bowtie \quad$ Maria Nowak

mt.nowak@poczta.umcs.lublin.pl

Paweł Sobolewski

pawel.sobolewski@umcs.eu

1 Instytut Matematyki UMCS, Pl. Marii Curie-Skłodowskiej 1, 20-031 Lublin, Poland 